\title{
Desempenho comparativo entre classificadores supervisionados no mapeamento de áreas de Ecótono em região de Caatinga
}

\author{
Comparative performance between classifiers supervised in mapping area of Ecotone in \\ region of Caatinga
}

\author{
Leandro Félix da Silva \\ Doutorando em Geografia na Universidade Federal da Paraíba, Brasil \\ felixhc.le@hotmail.com \\ Bartolomeu Israel de Souza \\ Professor na Universidade Federal da Paraíba, Brasil \\ bartolomeuisrael@,gmail.com \\ Vitor Matheus Bacani \\ Professor na Universidade Federal de Mato Grosso do Sul, Brasil \\ vitormbacani@gmail.com
}

\begin{abstract}
Resumo
Este estudo teve por finalidade avaliar o desempenho comparativo entre classificadores supervisionados no mapeamento de áreas de Ecótono em região de Caatinga entre os grandes afloramentos rochosos localizados na região da Área de Proteção Ambiental do Cariri no estado da Paraíba. Os procedimentos metodológicos se basearam nos métodos de classificação de Redes Neurais Artificiais (Neural Net), Máquina de Suporte de Vetores (Machine Support Vector - SVM); Mapeamento de Ângulo Espectral (Spectral Angle Mapper - SAM) e a Classificação Orientada a Objeto (Nearest Neighbor) que posteriormente foram validados pelos parâmetros estatísticos de Índice Kappa e Exatidão Global. Os resultados apontaram que os mapeamentos desenvolvidos pelos classificadores Neural Net e SVM foram os que apresentaram os melhores resultados, sendo ambos qualificados como excelente, seguido do SAM e Nearest Neighbor, ambos qualificados como muito bom pelo o Índice Kappa. Os resultados são importantes para criação de políticas de preservação e principalmente na gestão desses recursos naturais dentro da APA do Cariri e outras UC's localizadas na região com as mesmas características.
\end{abstract}

Palavras-chave: Área de Proteção Ambiental do Cariri, Plutão Bravo, Sentinel 2, Caatinga.

\begin{abstract}
This study aimed to evaluate the comparative performance between supervised classifiers in the mapping of Ecotone areas in region Caatinga between the large rocky outcrops located in the Cariri Environmental Protection Area (EPA) region of Paraíba state. The methodological procedures were based on the following classification methods: Neural Net, Support Vector Machine - SVM; Spectral Angle Mapper - SAM and Geographic Object-Based Image Analysis (GEOBIA) approach using Nearest Neighbor classifier that subsequently was validated by the Kappa Index and Global Accuracy statistical parameters. The results showed that the mappings developed by the Neural Net and SVM classifiers showed the best results, both being excellent, followed by SAM and Nearest Neighbor, both classified as very good by the Kappa Index. Results are essential for the creation of preservation policies and especially for the management of these natural resources within the Cariri EPA and other Conservation Units located in the region with the same characteristics.
\end{abstract}

Keywords: Cariri Environmental Protection Area, Pluton Bravo, Sentinel 2, Caatinga. 


\section{INTRODUÇÃO}

Uma das principais tarefas da atualidade sobre os estudos das paisagens é criar subsídios para uma cartografia que contemple o máximo de detalhes possível sobre as mesmas e suas peculiaridades. Nesse contexto, destacam-se as geotecnologias que atualmente vem potencializando e permitindo avanços significativos no mapeamento das paisagens.

Segundo Augusto (2016), com grande potencial de aplicabilidade na temática ambiental, os produtos obtidos por meio da tecnologia do sensoriamento remoto, como imagens de radar e imagens multiespectrais, vêm sendo extensamente utilizados nos últimos anos, tendo apresentado um grande crescimento em razão da expansão dos meios de processamento, dos baixos custos de capital, e pelo fato das imagens possuírem variadas escalas de tempo e de detalhamento espacial.

Vários métodos e técnicas vêm sendo desenvolvidos para que se possa analisar imagens fruto de sensores remotos com o maior grau de eficiência possível. Partindo desta perspectiva, podemos destacar os variados métodos de interpretação de imagens digitais a partir de utilização de uma infinidade de classificadores, lembrando que, ao efetuar esse procedimento automaticamente em uma paisagem, a partir de imagens de sensoriamento remoto, há o desafio de conseguir uma classificação precisa (MANANDHAR et al., 2009).

Conforme Campos et al. (2016), as classificações podem ser supervisionadas ou nãosupervisionadas. Os processos supervisionados associam o espaço espectral obtido por um sensor, com classes de cobertura da terra identificadas por um analista. As áreas identificadas são amostras dos atributos do espaço espectral, que fornecem regiões de treinamento para os parâmetros de um classificador. A aplicação de classificadores em geral, dá-se por critérios subjetivos e práticos, sendo os seus padrões de reconhecimento diretamente adotados na interpretação da imagem. A precisão da classificação pode ser melhorada usando uma combinação de classificadores, que potencializem a tomada de decisão, ou pela seleção do classificador com melhor desempenho (CAMPOS et al., 2016).

Neste sentido, o uso de aprimoradas técnicas de classificação de imagens de satélite permite o mapeamento de vários elementos da superfície terrestre, caracterizados como fundamentais para o monitoramento ambiental, principalmente sobre a vegetação e suas características físicas, biológicas, assim como vários estágios de crescimento, avanço, recuo e desmatamento.

Embora os diferentes tipos de vegetação no Brasil estejam teoricamente bem definidos, com base em critérios florísticos, fisionômicos e ecológicos (VELOSO et al., 1991), mapear e classificar a cobertura vegetal localizada nas áreas de transição entre os biomas brasileiros não é tarefa simples (HAIDAR et al., 2013). Segundo Silva et al., (2010) entre duas ou mais regiões 
ecológicas ou tipos de vegetação, existem sempre, ou pelo menos na maioria das vezes, comunidades indiferenciadas, onde as floras se interpenetram constituindo as transições florísticas ou contatos edáficos. Para Veloso et al., (1991) essas transições florísticas se referem ao "mosaico específico" ou ao próprio Ecótono, ou seja, é o contato entre tipos de vegetação com estruturas fisionômicas semelhantes, cujas espécies se misturam.

$\mathrm{Na}$ região do semiárido brasileiro, onde as paisagens caracterizam-se por apresentar uma vegetação do tipo caducifólia, má distribuição das chuvas no tempo e no espaço, baixos índices pluviométricos associados a prolongados períodos de estiagem, temperaturas elevadas, solos rasos e pedregosos e rios intermitentes, o papel de proteção desempenhado pela vegetação torna-se ainda mais importante para sustentação desses ecossistemas (LIMA; ALMEIDA, 2017).

Devido a suas características, os ecossistemas dessa região são importantes unidades geográficas que se apresentam sob peculiaridades ambientais, variabilidade de habitats, endemismos e uma rica biodiversidade constituída por fauna e flora únicas (LEAL et al., 2005). Bastos e Cordeiro (2012 p. 9) afirmam que "dentre os domínios morfoclimáticos brasileiros a caatinga é o que apresenta a maior variedade fitogeográfica com vários padrões de caatingas, núcleos de matas úmidas, cerrados e de matas ciliares" (LIMA; ALMEIDA, 2017).

De forma mais específica, uma característica importante dessa região é a presença de grandes afloramentos rochosos (denominados popularmente de lajedos) que durante a estação chuvosa, desempenham um papel fundamental no ciclo hidrológico da região devido a sua estrutura impermeável, o que favorece a ocorrência de intenso escoamento superficial, o qual irá beneficiar as áreas de seu entorno imediato, tornando-as mais úmidas, possibilitando que ocorra a presença de uma Caatinga com estrutura florestal raramente encontrada fora dos seus entornos, contemplando também a presença de algumas outras espécies pertencentes a outros biomas como Cerrado e Mata Atlântica, de condições subúmidas e úmidas, compondo portanto um Ecótono, o que ajuda a confirmar a ideia de que essas formas de relevo constituem-se em importantes refúgios ecológicos regionais (POREMBSKY, 2000; SARTHOU et al. 2007; LUNGUINHO et al., 2015: CORDEIRO et al., 2018).

Em função do exposto, este trabalho tem por finalidade avaliar o desempenho comparativo entre classificadores supervisionados no mapeamento de áreas de Ecótono em região de Caatinga, entre os grandes afloramentos rochosos localizados na Área de Preservação Ambiental - APA do Cariri, no estado da Paraíba, Brasil. 


\section{METODOLOGIA}

\section{1. Área de estudo}

A área estudada é um conjunto de grandes afloramentos rochosos localizada na região da APA do Cariri que fica entre os municípios de Boa Vista, Cabaceiras e São João do Cariri, entre as latitudes $07^{\circ} 20^{\prime} 30^{\prime \prime}$ e $07^{\circ} 23^{\prime} 30^{\prime \prime}(\mathrm{S})$ e longitudes $36^{\circ} 20^{\prime} 30^{\prime \prime}$ e $36^{\circ} 13^{\prime} 30^{\prime \prime}(\mathrm{W})$, com uma área de aproximadamente $34 \mathrm{~km}$ de extensão na região central do estado da Paraíba, conforme apresentado na Figura 1.

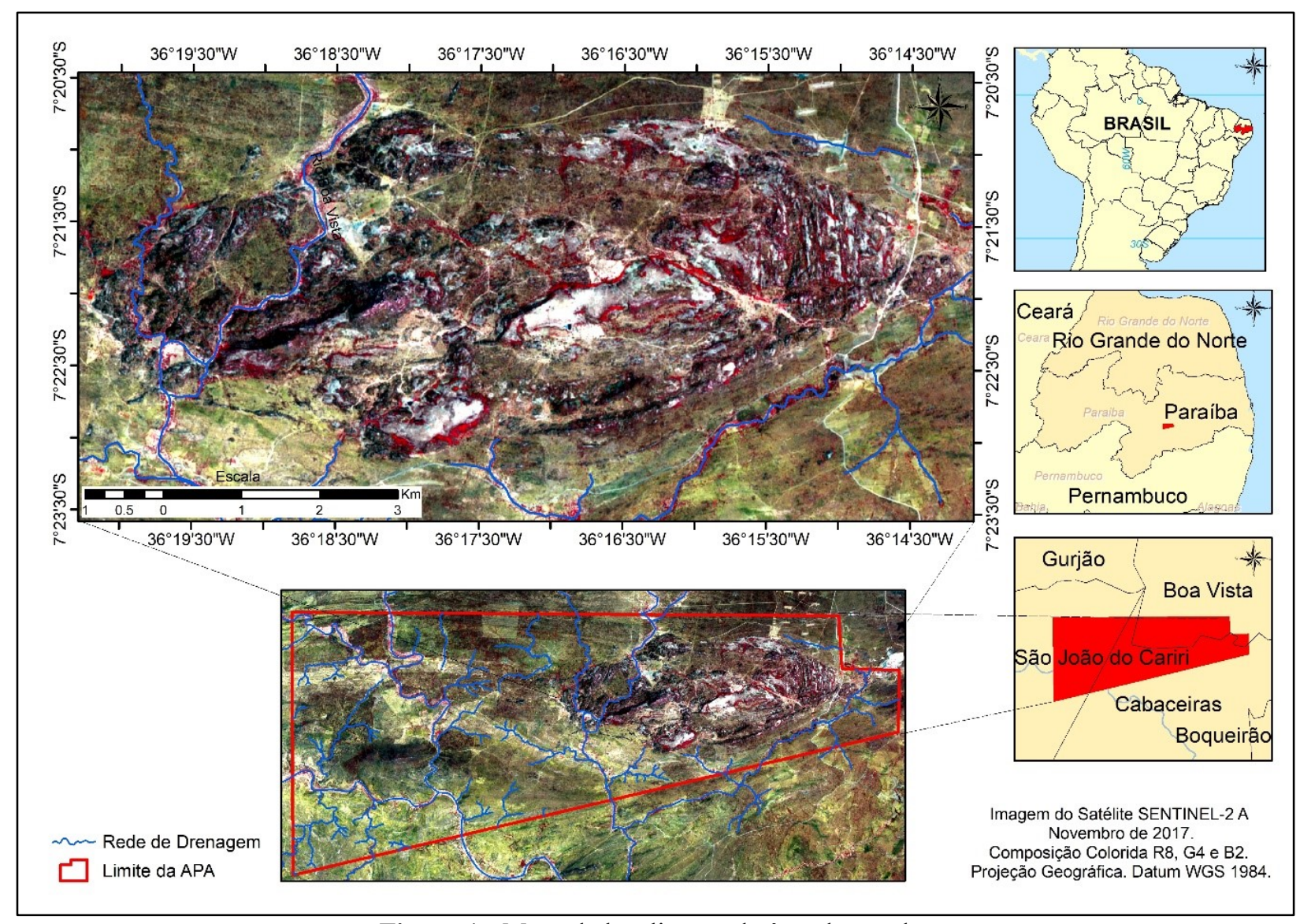

Figura 1 - Mapa de localização da área de estudo.

A APA do Cariri está situada no semiárido paraibano, na microrregião conhecida como Cariri Velhos, tendo sido criada pela Secretaria de Meio Ambiente do Estado da Paraíba, pelo Decreto Estadual 25.083 de 8 de junho de 2004 (PARAÍBA, 2004).

Essa região é formada por grandes afloramentos rochosos que, geologicamente compõe um conjunto denominado Plutão Bravo, onde ocorrem rochas do tipo magmáticas e metamórficas (Figura 2) como granitos, gnaisses, filitos, xistos e migmatitos (CARVALHO, 1982) pertencentes as suítes graníticas ediacaranas na Suíte Intrusiva Itaporanga, localizado no Domínio da Zona Transversal (CPRM, 2017). 


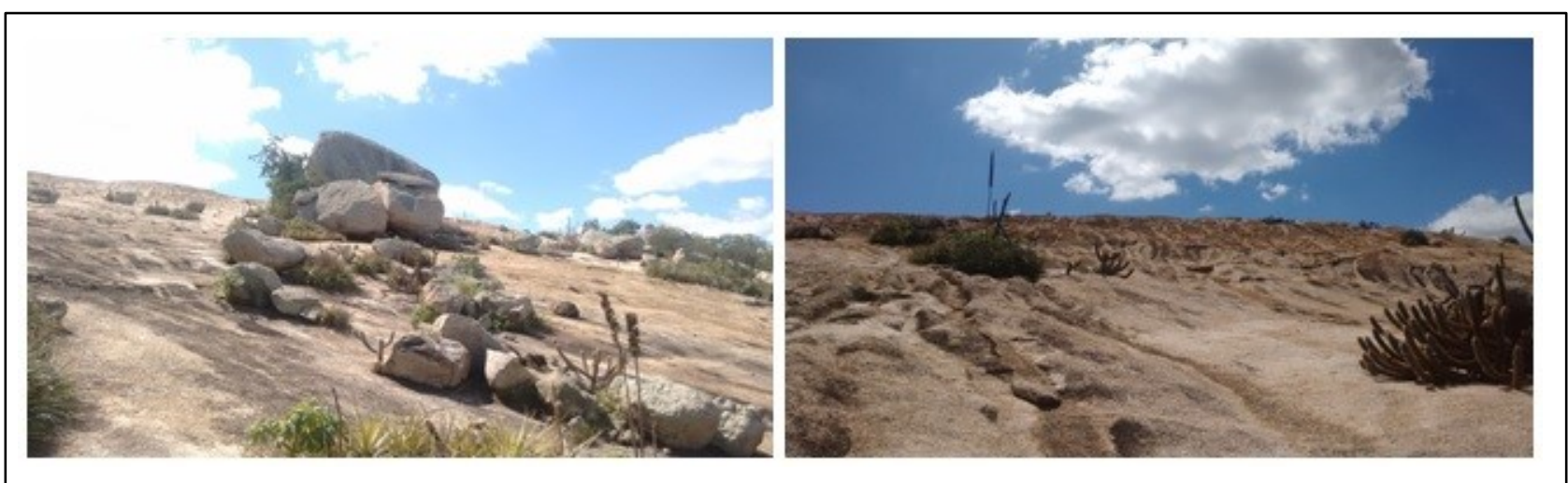

Figura 2 - Afloramentos Rochosos no Plutão Bravo.

Segundo Romano et al., (2018), o Plutão Bravo consiste num Stock elipsoidal formado por monzosienogranitos, porfiríticos (textura de grandes cristais), enclaves (envolta de material metamórfico), e zonas híbridas, de minerais metaluminosos e levemente peraluminosos. O Plutão Bravo aflora no centro-leste da Paraíba, na localidade de Bravo, município de Cabaceiras, e foi alojado em ortognaisses graníticos de alto teor metamórfico.

Na superfície, o Plutão Bravo apresenta forma elipsoidal, com aproximadamente $12 \mathrm{~km}$ de comprimento por $5 \mathrm{~km}$ de largura, contendo diversas formas de lajedos locais (Figura 3), sendo os mais conhecidos os do Pai Mateus, da Salambaia, do Bravo, Manoel de Souza e a Saca de Lã (SOUSA e XAVIER, 2017) e que devido a beleza cênica desta região se tornou um importante atrativo turístico.

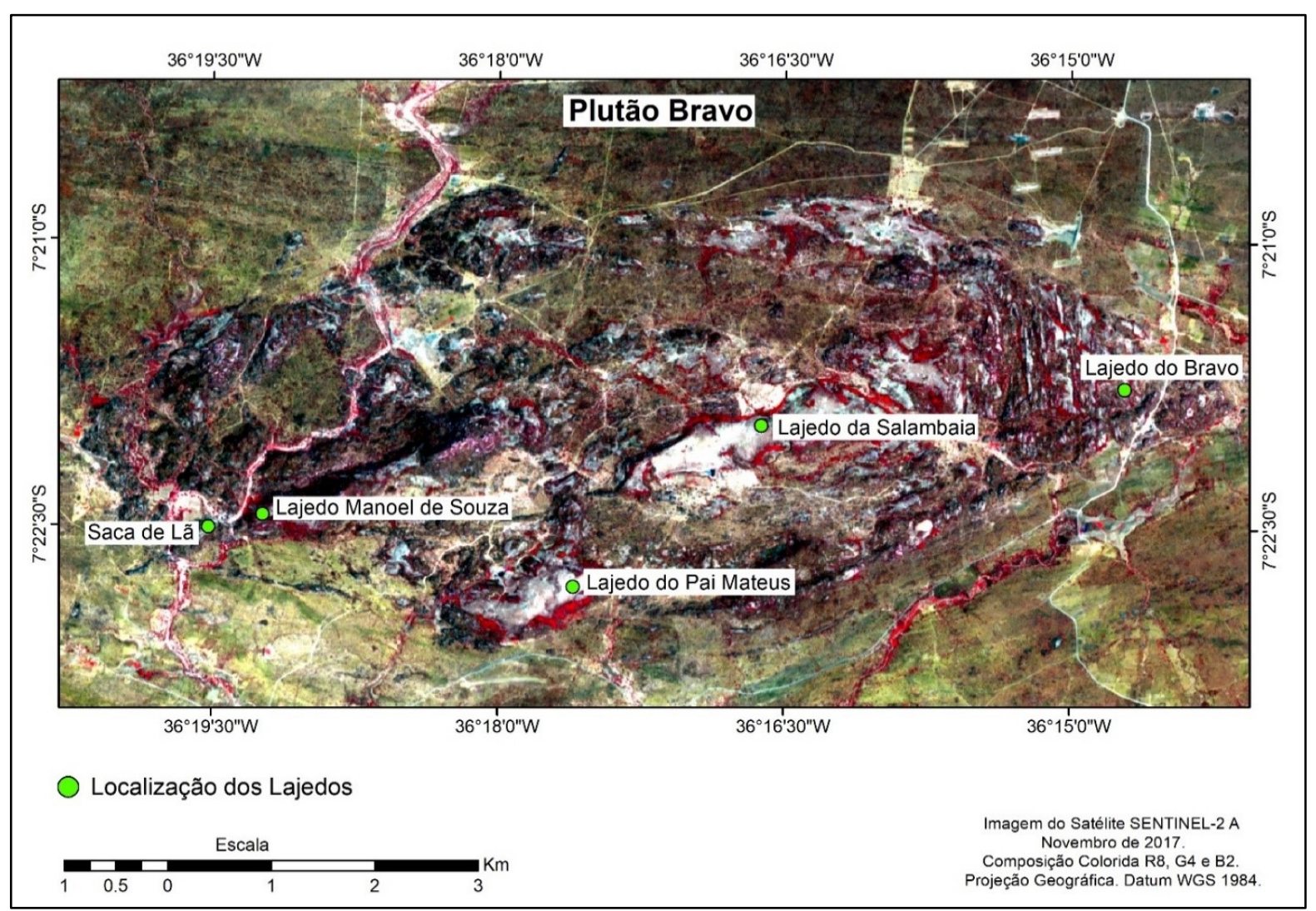

Figura 3 - Região do Plutão Bravo e os pontos dos lajedos. 
A vegetação dominante é composta predominantemente por Caatinga do tipo arbustiva (Figura 4) contendo espécies como o Pinhão Bravo (Jatropha mollissima), Marmeleiro (Croton blanchetianus), Catingueira (Poincianella pyramidalis), Pereiro (Aspidosperma pyrifolium), Jurema-preta (Mimosa tenuiflora), Favela (Cnodusculus quercifolius). Encontra-se também algumas espécies arbóreas-arbustivas isoladas como o Juazeiro (Ziziphus joazeiro), Umbu (Spondias tuberosa) e o Mulungu (Erythrina velutina). Um outro grupo bastante abundante é a família das cactáceas, com espécies como o Xique-xique (Pilosocereus gounellei), Mandacaru (Cereus jamacaru), Coroa-de-frade (Melocactus bahiensis) e Palmatória de espinho (Tacinga palmadora), além da presença de algumas bromeliáceas como a Macambira (Bromelia laciniosa) entre outros arbustos e herbáceas que se espalham rapidamente no período chuvoso (SOUZA e SOUZA, 2016; LACERDA et al., 2018; SILVA et al., 2019a).

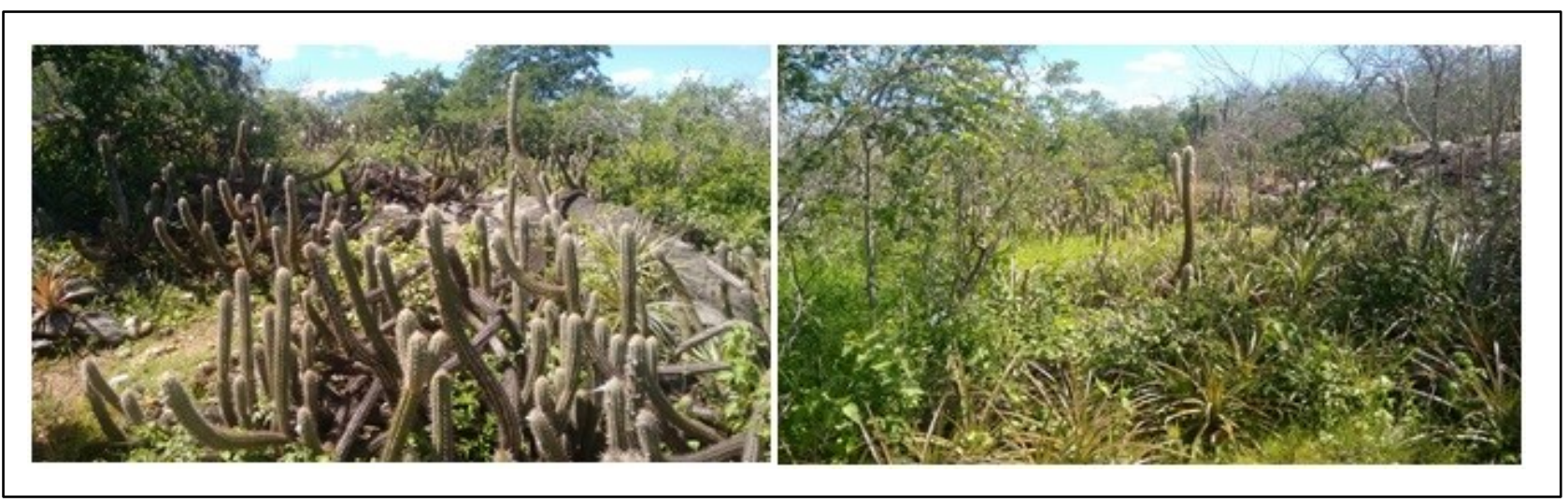

Figura 4 - Caatinga Arbustiva.

O Ecótono (Figura 5) dessa área tem como característica uma estreita faixa de aproximadamente 10 a 20 metros de largura localizada entre os afloramentos rochosos (lajedos) formada basicamente por espécies vegetais de porte arbóreo alto, como Angico (Anadenanthera colubrina), Aroeira (Myracrodruon urundeuva), Imburana-de-cambão (Commiphora leptophloeos), Faxeiro (Pilosocereus pachycladus), Mororó (Bauhinia cheilantha) e Ipê-roxo (Handroanthus impetiginosus), típicas de Caatinga, além de Carnaúba (Copernicia prunifera), espécie de Mata Ciliar na Caatinga, Tamboril (Enterolobium contortisiliquum), ocorrente em áreas mais úmidas da Caatinga e também no Cerrado, além de Pau-ferro (Caesalpinia férrea var. Leiostachya), Jatobá (Hymenaea rubriflora) e Jenipapo-bravo (Tocoyena formosa) ocorrentes em áreas de Mata Atlântica (SILVA et al., 2019a). 

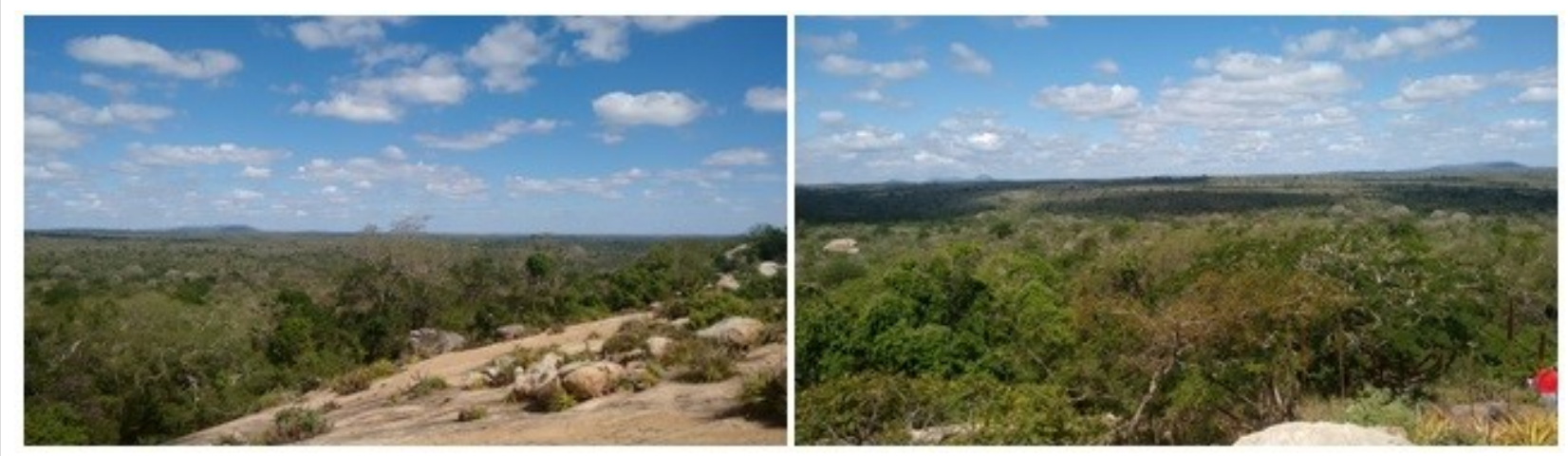

Figura 5 - Área do Ecótono no entorno do lajedo com caatinga arbustiva em frente.

Lunguinho et al. (2015), identificaram nesta área a presença de 83 espécies diferentes, número elevado considerando a sua localização em um bioma como a Caatinga, onde domina principalmente uma condição de clima semiárido. 11 dessas espécies identificadas têm sua ocorrência original vinculada exclusivamente a Mata Atlântica, Cerrado e Floresta Amazônica, biomas onde ocorrem maior pluviosidade e umidade.

Segundo Lunguinho et al., (2015) o solo predominante nestas áreas da base dos lajedos é o Neossolo Regolítico, com profundidade média entre 1,50 a 2m. Em comparação ao solo Luvissolo Crômico, dominante no restante da região, com média de profundidade de $60 \mathrm{~cm}$, a presença do Neossolo Regolítico confere a estas áreas maior potencial de aproveitamento da água escoada dos afloramentos rochosos, o que lhe dá maior capacidade de sustentar espécies vegetais mais exigentes em recursos hídricos.

O clima foi classificado por Köppen (1931) como semiárido (BSh) com temperaturas médias anuais elevadas (que variam entre de $25^{\circ}$ e $27^{\circ} \mathrm{C}$ ), com uma precipitação média anual entre 400 e 500 mm (AESA, 2018) características que fazem dessa região a mais seca do país (SOUZA et al., 2009).

\subsection{Procedimentos metodológicos}

Os procedimentos metodológicos foram organizados e executados conforme exemplifica a Figura 6 (Fluxograma). 


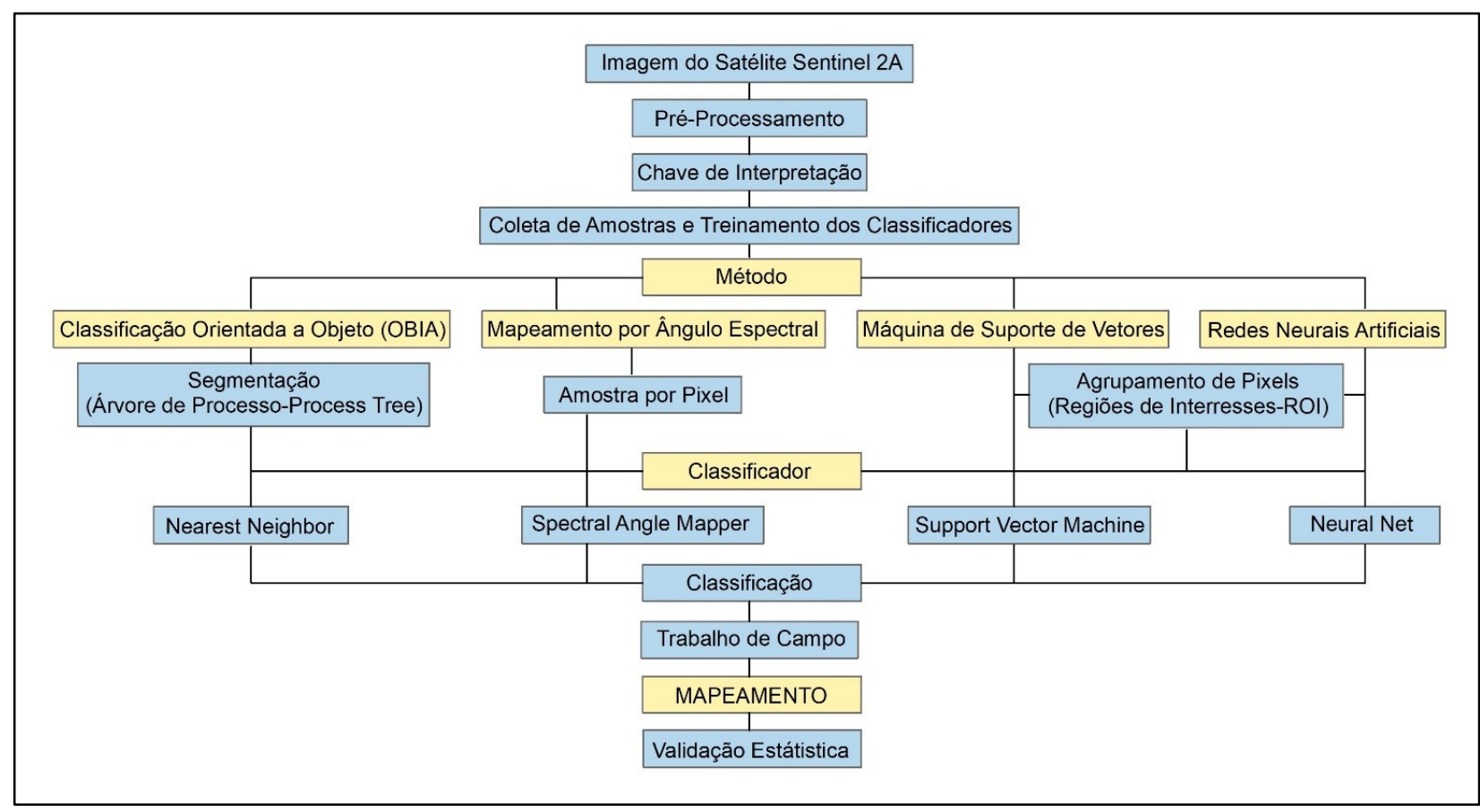

Figura 6 - Fluxograma metodológico.

\subsection{Pré-processamento}

Para o desenvolvimento deste estudo foi utilizada a imagem do satélite SENTINEL-2A de 17 de novembro de 2017. Optou-se pelo referido satélite por ele oferecer imagens com resolução espacial de 10 metros, além da disponibilidade gratuita e por conter imagens livres de nuvens, que foram extraídas do banco de dados online da Agência Espacial Europeia (European Space Agency ESA).

O pré-processamento da imagem foi desenvolvido no software QGis 3.0, a partir da ferramenta Processing, em seguida, na aba Sentinel 2 conversion aplicando a correção radiométrica das 12 bandas da imagem do satélite Sentinel-2A. Ao termino do processo de correção, as bandas 2, 3, 4, e 8 foram convertidas do formato jp2 para o formato TIF/GEOTIFF e inseridas no software ArcGis 10.3 (ESRI, 2012) no qual foram unidas para criação do processo de falsa-cor, no intuito de realçar as classes de interesse com contrastes Linear de 5\%. E por fim, foi realizado o recorte de área de estudo através da inserção do limite da área estudada no formato Shapefile na escala de $1: 25.000$.

\subsection{Chave de interpretação}

A chave de interpretação foi desenvolvida para auxiliar na identificação dos elementos contidos na imagem. A interpretação dos alvos foi feita a partir da associação das características de 3 classes a serem mapeadas: 1) Afloramento Rochoso: 2) Caatinga e 3) Ecótono, baseados nos levantamentos de pontos de GNSS (Sistema Global de Navegação por Satélite) obtidos em campo 
de cada uma das classes, que foram associados a quatro elementos interpretativos na imagem como cor, tonalidade, textura e forma, conforme descrito por Florenzano (2011), da composição colorida R8, G4 e B2 na imagem do satélite SENTINEL-2A, conforme demonstra a Figura 7.

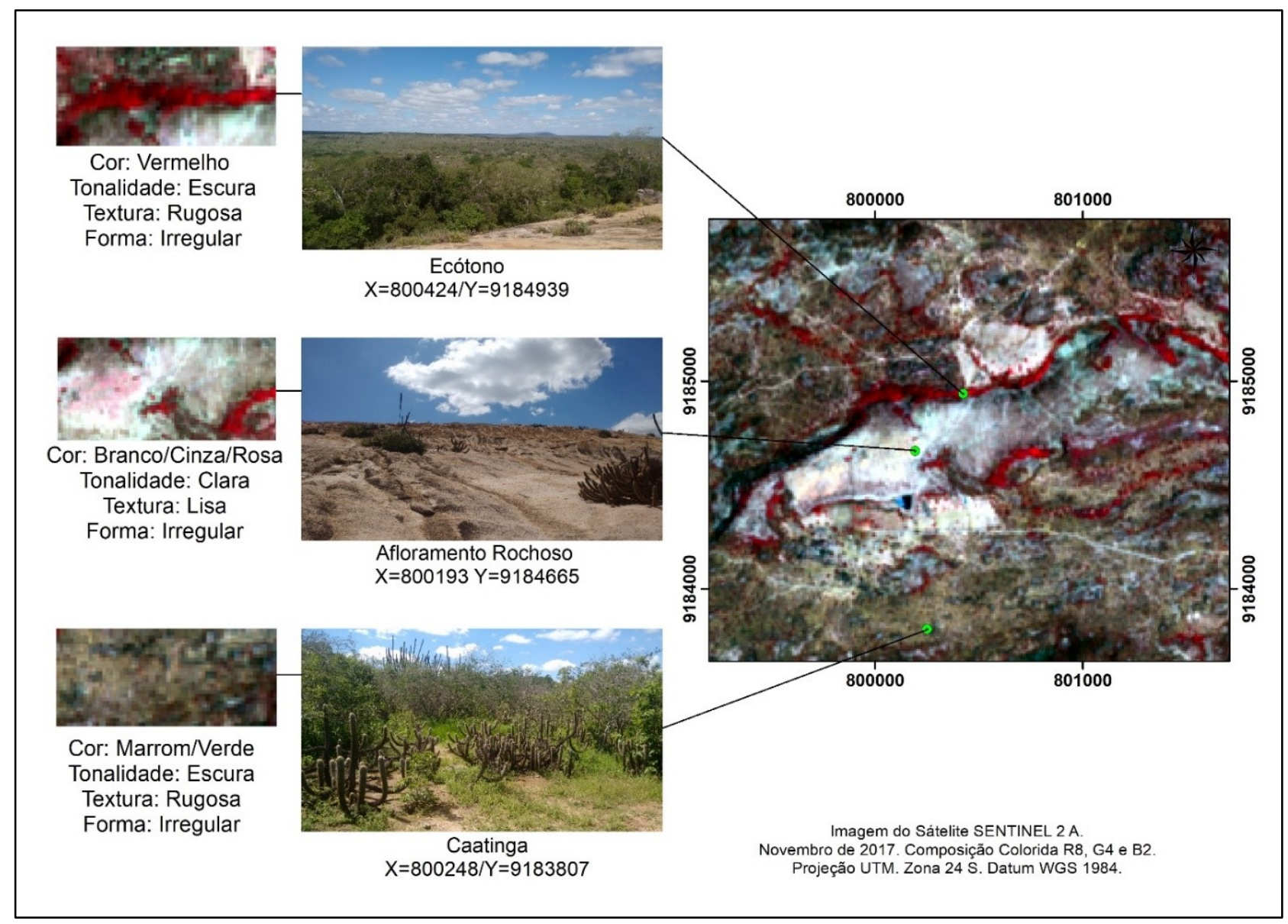

Figura 7 - Chave de interpretação.

\subsection{Coleta de amostras para o treinamento dos classificadores}

Os métodos utilizados para a classificação foram as Redes Neurais Artificias a partir do classificador Neural Net; Máquina de Suporte de Vetores classificador Support Vector Machine SVM; Mapeamento de Ângulo Espectral classificador Spectral Angle Mapper e a Classificação Orientada a Objeto (OBIA) com o classificador Nearest Neighbor.

A coleta de amostras utilizadas para o treinamento de cada classificador ocorreu da seguinte forma: I) agrupamento de pixels a partir da criação de regiões de interesses (Regions of Interest - ROI) para os classificadores Neural Net e Support Vector Machine; II) amostra por pixel para o Spectral Angle Mapper (SAM) ambos no software ENVI 5.3 (EXELIS, 2014) e III) processo de segmentação utilizando árvore de processo (Process Tree) para a classificação orientada a objeto (OBIA) no software eCognition 8.3 (TRIMBLE, 2015), conforme descrito nas seguintes etapas: 
I. Agrupamento de Pixels: foram criados polígonos ao em torno dos pixels de cada alvo escolhido de acordo com as características da chave de interpretação, que foram agrupados a partir da ferramenta Regions of Interest (ROI) no software ENVI 5.3 (EXELIS, 2014), para cada uma das classes a serem mapeada de Afloramento Rochoso, Caatinga e Ecótono. Foram gerados cerca de 50 polígonos para cada classe espalhados ao longo da imagem, como amostras para o treinamento dos classificadores Neural Net e Support Vector Machine.

II. Amostra por Pixel: Foram selecionadas amostras individuais de pixel de referência de cada classe, que foram classificadas a partir do domínio espectral com base nos ângulos dos vetores de brilho das bandas espectrais. Os limites de decisão são estabelecidos pela indicação do menor ângulo entre cada pixel e os espectros de referência das bibliotecas da imagem (CAMPOS et al., 2016) a partir da ferramenta Spectral Profile no software ENVI 5.3 (EXELIS, 2014). Neste caso, optamos em apontar 3 amostras de pixel para a classe Afloramento Rochoso, 4 amostras para a classe Caatinga e 5 amostras para a classe Ecótono devido as variações espectrais que cada alvo apresenta para a mesma classe. Cada amostra de pixel foi baseada principalmente nos pontos obtidos a campo por receptor GNSS referente a cada classe que foram plotados na imagem e auxiliado pela chave de interpretação. Em seguida, as amostras foram submetidas ao classificador Spectral Angle Mapper, também no software ENVI 5.3 (EXELIS, 2014).

III. Segmentação: A segmentação foi desenvolvida no software eCognition 8.3 (TRIMBLE, 2015) e partiu da utilização da árvore de processo (Process Tree), no qual foram ajustados parâmetros de descrição como o algoritmo de segmentação a ser utilizado e a composição do critério de homogeneidade para o processo de segmentação da imagem. Primeiro definiu-se o Multiresolution Segmentation como o algoritmo para segmentação, na sequência atribuiu-se pesos (valores) de relevância para cada banda da imagem do SENTINEL-2A, através da opção Segmentation Settings, conforme demonstra a Quadro 1. 
Quadro 1 - Valores de relevância utilizados para cada banda do Sentinel-2A no processo de segmentação.

\begin{tabular}{ccc}
\hline Bandas Sentinel-2A & $\begin{array}{c}\text { Segmentation Settings } \\
\text { Comprimento de Onda }\end{array}$ & Valor Atribuído \\
\hline 2 & $490 \mu \mathrm{m}$ & 1 \\
3 & $560 \mu \mathrm{m}$ & 1 \\
4 & $665 \mu \mathrm{m}$ & 1 \\
8 & $842 \mu \mathrm{m}$ & 10 \\
\hline
\end{tabular}

Os valores variaram de 1 a 10 , sendo que o valor 10 foi atribuído a banda 8 do SENTINEL-2A, referente ao comprimento de onda na região do Infravermelho Próximo (0.76 $0.90 \mu \mathrm{m})$, no intuito de destacar a vegetação de porte arbóreo no processo de segmentação. Outro parâmetro realizado foi a composição do critério de homogeneidade (Composition of Homogeneity Criterion), que leva em consideração atributos como escala, compacidade e forma dos objetos a serem segmentados, do qual, após vários testes de segmentação realizados, chegamos aos valores de 1 para escala, 0,006 para forma e 0,005 para compacidade. A classificação orientada a objeto foi executada através do classificador Nearest Neighbor (Vizinho Mais Próximo).

\subsection{Trabalho de campo}

O trabalho de campo foi realizado de 07 a 10 de setembro de 2017 (estação seca) e de 15 a 18 de abril de 2018 (estação chuvosa), levando em consideração as características impressas à cobertura vegetal, conforme a presença ou ausência de chuvas na região. Os dados obtidos para validação do mapeamento foram efetuados a partir de fotografias e da coleta de aproximadamente 300 pontos por receptor GNSS.

\subsection{Validação estatística}

O método avaliativo utilizado para validar os mapeamentos desenvolvidos foi a Matriz de Confusão (CONGALTON, 1991), composta pelos coeficientes de Exatidão Global e Índice Kappa. Foram utilizados 350 pontos para a classe Afloramento Rochoso, 350 para Caatinga e 348 para o Ecótono, totalizando 1.048 pontos de verdades terrestres, divididos em pontos de GNSS coletados a campo das 3 classes temáticas mapeadas e outros pontos que foram distribuídos aleatoriamente pela imagem de satélite.

Em seguida, os pontos foram inseridos no software ENVI 5.3 (EXELIS, 2014), convertidos para o formato ROI e submetidos ao processo de validação, utilizando as ferramentas Classification - Post Classification - Confusion Matrix Using Ground Truth Image. Por fim, os valores obtidos da Exatidão Global e Índice Kappa foram comparados aos limiares estabelecidos por Landis e Koch (1977), conforme exemplifica o Quadro 2. 
Quadro 2 - Qualificação de acordo com o Índice Kappa.

\begin{tabular}{|c|c|}
\hline Índice Kappa & Concordância \\
\hline 0,00 & Péssima \\
\hline 0,01 a 0,20 & Ruim \\
\hline 0,21 a 0,40 & Razoável \\
\hline 0,41 a 0,60 & Bom \\
\hline 0,61 a 0,80 & Muito Bom \\
\hline 0,81 a 1,00 & Excelente \\
\hline
\end{tabular}

Fonte: Landis e Koch (1977).

\section{RESULTADOS E DISCUSSÃO}

Com o uso das técnicas empregadas, obteve-se como resultados 4 mapas (Figura 8), um de cada classificador: 1) Neural Net; 2) Support Vector Machine (SVM); 3) Spectral Angle Mapper (SAM) e 4) Nearest Neighbor, composto pelas classes Ecótono, Caatinga e Afloramento Rochoso.

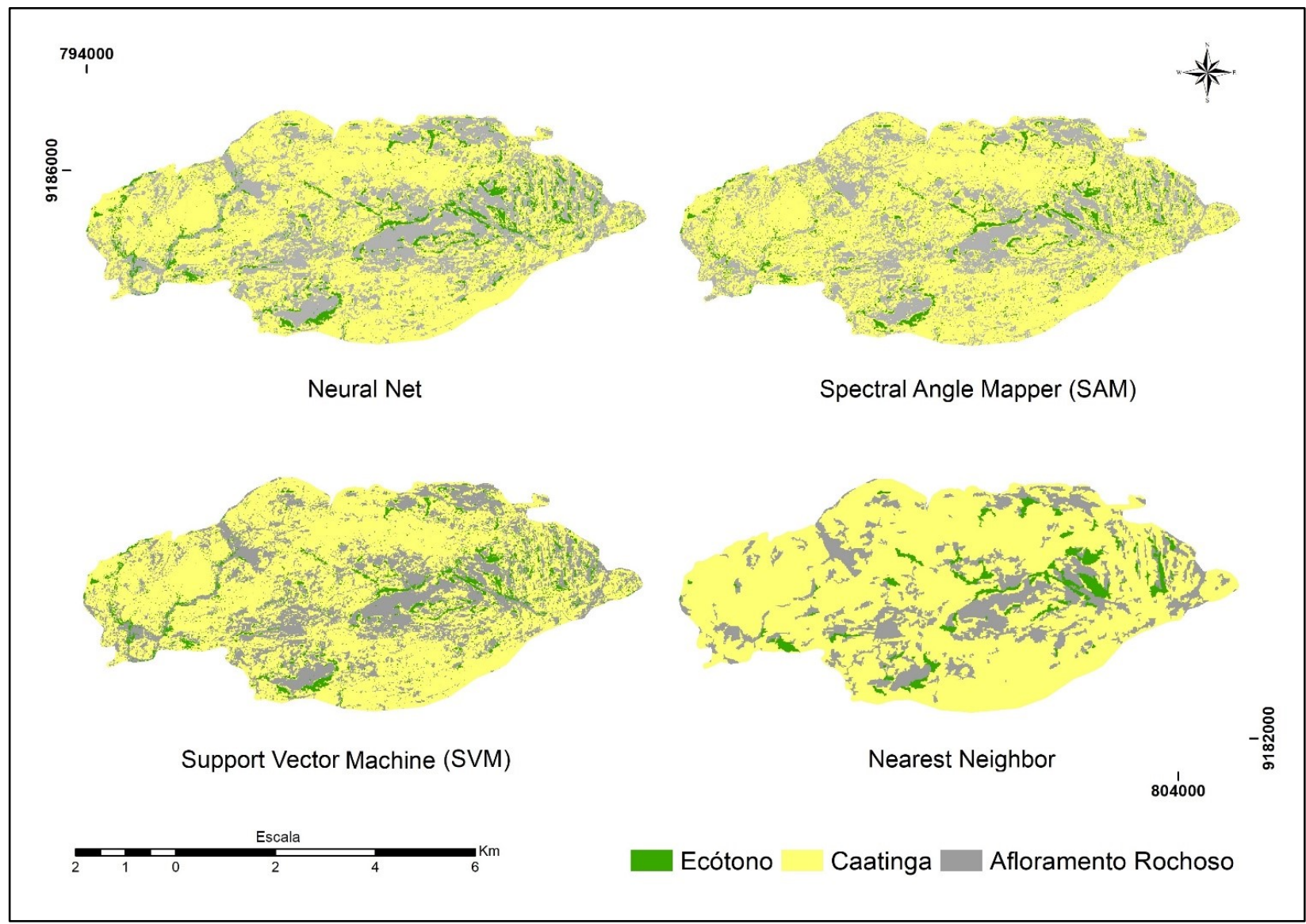

Figura 8 - Resultado do mapeamento da área dos 4 classificadores.

O Quadro 3 representa o desempenho de cada classificador a partir da avaliação estatística, utilizando o Índice Kappa e Acurácia Global, qualificados posteriormente de acordo com os limiares estabelecidos por Lands e Koch (1977). 
Quadro 3 - Desempenho do mapeamento utilizando classificadores supervisionados.

\begin{tabular}{ccccc}
\hline Classificador & Índice Kappa & Qualificação & Acurácia Global & Qualificação \\
\hline Neural Net & 0.8139 & Excelente & $87.5954 \%$ & Excelente \\
Support Vector Machine (SVM) & 0.8024 & Excelente & $86.8321 \%$ & Excelente \\
Spectral Angle Mapper (SAM) & 0.7365 & Muito Bom & $82.4427 \%$ & Excelente \\
Nearest Neighbor & 0.6191 & Muito Bom & $74.6183 \%$ & Muito Bom \\
\hline
\end{tabular}

O classificador Neural Net apresentou os maiores valores tanto para o Índice Kappa quanto para Acurácia Global, ambos classificados como excelentes, de acordo com os limiares estabelecidos por Lands e Koch (1977). O Quadro 4 apresenta os valores da matriz de confusão individual do mapeamento desenvolvido pelo algoritmo de redes neurais (Neural Net).

Quadro 4 - Matriz de confusão do mapeamento desenvolvido pelo classificador Neural Net.

\begin{tabular}{ccccc}
\hline Neural Net & \multicolumn{2}{c}{ Classe Mapeada } & Pontos de Controle \\
\hline Classe Mapeada & Afloramento Rochoso & Caatinga & Ecótono & Total \\
Afloramento Rochoso & 343 & 28 & 3 & 374 \\
Caatinga & 7 & 316 & 86 & 409 \\
Ecótono & 0 & 6 & 259 & 265 \\
Total & 350 & 350 & 348 & 1.048 \\
\hline Índice Kappa & 0.8139 & & Qualificação & Excelente \\
Acurácia Global & $87.5954 \%$ & & Qualificação & Excelente \\
\hline
\end{tabular}

Ao analisar a matriz de confusão do mapeamento pelo classificador de redes neurais (Neural Net), observa-se que os maiores conflitos estão entre as classes Caatinga e Ecótono. O Quadro 5 demonstra os valores de acurácia do produtor e acurácia do usuário.

Quadro 5 - Acurácia do produtor e acurácia do usuário para o classificador Neural Net.

\begin{tabular}{ccccc}
\hline Classe Mapeada & $\begin{array}{c}\text { Acurácia do } \\
\text { Produtor em \% }\end{array}$ & $\begin{array}{c}\text { Acurácia do } \\
\text { Usuário em \% }\end{array}$ & $\begin{array}{c}\text { Acurácia do } \\
\text { Produtor por } \\
\text { Pixel }\end{array}$ & $\begin{array}{c}\text { Acurácia do } \\
\text { Usuário por } \\
\text { Pixel }\end{array}$ \\
\hline Afloramento Rochoso & 98.00 & 91.71 & $343 / 350$ & $343 / 374$ \\
Caatinga & 90.29 & 77.26 & $316 / 350$ & $316 / 409$ \\
Ecótono & 74.43 & 97.74 & $259 / 348$ & $259 / 265$ \\
Total & $\mathbf{1 0 0 \%}$ & $\mathbf{1 0 0 \%}$ & $\mathbf{9 1 8} / \mathbf{1 . 0 4 8}$ & $\mathbf{9 1 8} / \mathbf{1 . 0 4 8}$ \\
\hline
\end{tabular}

Dos 348 pontos de verdade terrestres utilizados para validar a classe Ecótono, 259 foram confirmados como áreas de Ecótono, representando uma acurácia do produtor de 74, 43\% qualificado como muito bom e 97.74\% de acurácia do usuário qualificado como excelente. Já para a Caatinga, a acurácia do produtor apresentou um valor de $90.29 \%$ (Excelente) enquanto que para o acurácia do usuário 77.26\%, (Muito Bom). A classe Afloramento Rochoso apresentou um pouco de confusão com Caatinga e com Ecótono, porém foi a que obteve maior avaliação na acurácia do 
produtor, com $98.00 \%$ e $91.71 \%$ de acurácia de usuário, ambos qualificados como excelente, levando em consideração os limiares estabelecidos por Lands e Koch (1977).

O classificador Neural Net destacou-se em detrimento dos demais classificadores analisados, na separação entre as classes Ecótono e Caatinga, principalmente pelo número baixo de erros de confusão entre as duas classes que estão relacionadas a vegetação e consequentemente pelo número mais elevado de acertos da classe Ecótono (259 pontos), conforme analisados na matriz de confusão.

Resultados satisfatórios utilizando classificadores baseados em redes neurais na separação de alvos como vegetação também foram obtidos por Chagas et al., (2009) e Silva et al. (2013), ao classificarem com eficiência diferentes níveis de degradação de pastagens, além da vegetação de tipo arbustivo e arbóreo como plantações de café e mata. Assim como Pereira e Centeno (2017), que também tiveram resultados bastantes satisfatórios utilizando classificadores de redes neurais na identificação de árvores em ambientes urbanos, chegando a 98,03\% de acurácia, a partir de dados como a informação espectral (RGB) combinados com a altimetria. Comparado os resultados dos autores citados com os resultados obtidos neste estudo, nota-se uma proximidade principalmente nos valores de acurácia de ambos mapeamentos relacionados a vegetação de porte arbóreo, o qual é o principal objetivo deste trabalho.

Cabe destacar que outros trabalhos utilizando classificadores baseados em redes neurais também estão sendo utilizados para uma infinidade de mapeamentos com diferentes técnicas (GONÇALVES et al., 2008; ARRUDA et al., 2013 e FERNANDES et al., 2017) apresentando ótimos resultados sobre a eficiência desse tipo de classificação.

O mapeamento desenvolvido pelo classificador SVM foi qualificado como excelente tanto para o Índice Kappa e Acurácia Global. Neste caso também houve confusão da classe Ecótono com a classe Caatinga. O Afloramento Rochoso teve maiores confusões com a classe Caatinga conforme demonstra o Quadro 6, contendo a matriz de confusão.

Quadro 6 - Matriz de confusão do mapeamento desenvolvido pelo classificador Support Vector Machine - SVM.

\begin{tabular}{ccccc}
\hline Suporte Vector Machine (SVM) & \multicolumn{1}{c}{ Classe Mapeada } & & Pontos de Controle \\
\hline Classe Mapeada & Afloramento Rochoso & Caatinga & Ecótono & Total \\
Afloramento Rochoso & 342 & 25 & 2 & 369 \\
Caatinga & 8 & 321 & 99 & 428 \\
Ecótono & 0 & 4 & 247 & 251 \\
Total & 350 & 350 & 348 & 1.048 \\
\hline Índice Kappa & 0.8024 & & Qualificação & Excelente \\
Acurácia Global & $86.8321 \%$ & & Qualificação & Excelente \\
\hline
\end{tabular}


No critério acurácia do produtor e do usuário para o classificador SVM, a classe Ecótono apresentou 70.98\% (Muito Bom) para o produtor e 98.41\% (Excelente) para o usuário, conforme o Quadro 7.

Quadro 7 - Acurácia do produtor e a Acurácia do usuário para o classificador Support Vector Machine - SVM.

\begin{tabular}{ccccc}
\hline Classe Mapeada & $\begin{array}{c}\text { Acurácia do } \\
\text { Produtor em \% }\end{array}$ & $\begin{array}{c}\text { Acurácia do } \\
\text { Usuário em \% }\end{array}$ & $\begin{array}{c}\text { Acurácia do } \\
\text { Produtor por } \\
\text { Pixel }\end{array}$ & $\begin{array}{c}\text { Acurácia do } \\
\text { Usuário por } \\
\text { Pixel }\end{array}$ \\
\hline Afloramento Rochoso & 97.71 & 92.68 & $342 / 350$ & $342 / 369$ \\
Caatinga & 91.71 & 75.00 & $321 / 350$ & $321 / 428$ \\
Ecótono & 70.98 & 98.41 & $247 / 348$ & $247 / 251$ \\
Total & $\mathbf{1 0 0 \%}$ & $\mathbf{1 0 0 \%}$ & $\mathbf{9 1 0 / 1 . 0 4 8}$ & $\mathbf{9 1 0 / 1 . 0 4 8}$ \\
\hline
\end{tabular}

Para a Caatinga os valores de acurácia do produtor foram de 91.71\% (Excelente) e 75.00\% (Muito Bom) para acurácia de usuário. O Afloramento Rochoso apresentou valores superiores a 90\% considerados como excelentes para ambos os critérios.

O mapeamento executado pelo classificador SVM apresentou o segundo melhor resultado em comparação aos demais classificadores analisados, obtendo um número menor de acertos da classe Ecótono (247 pontos), assim como o aumento de erros de confusão com a classe Caatinga, comparados ao classificador Neural Net.

Outros trabalhos utilizando o classificador SVM na distinção de fisionomias vegetais também obtiveram valores que atingiram limiares de 0,80, considerados excelente, como Andrade et al., (2014), Moreira et al., (2014) e Lenzi e Nunes (2016), resultados parecidos com o obtido neste estudo. Já Sothe et al., (2017) e Miguel e Sano (2019) não obtiveram resultados com valores elevados de acurácia acima de 0,80 utilizando o classificador SVM para mapeamento de uso da terra e cobertura vegetal, porém os números encontrados por ambos foram superiores ao de 0,60 indicando o grau de eficiência do classificador.

$\mathrm{O}$ resultado do mapeamento do classificador SAM apresentou um Índice Kappa qualificado como muito bom e uma Acurácia Global como excelente. Ao analisar a matriz de confusão (Quadro 8) pôde-se observar que houve um aumento significativo no número de pontos de confusão entre as classes Ecótono e Caatinga, quando comparado com os outros dois classificadores anteriores, automaticamente reduzindo o número de acertos das áreas de Ecótono. 
Quadro 8 - Matriz de confusão do mapeamento desenvolvido pelo classificador Spectral Angle Mapper - SAM.

\begin{tabular}{ccccc}
\hline Spectral Angle Mapper (SAM) & \multicolumn{2}{c}{ Classe Mapeada } & \multicolumn{2}{c}{ Pontos de Controle } \\
\hline Classe Mapeada & Afloramento Rochoso & Caatinga & Ecótono & Total \\
Afloramento Rochoso & 345 & 20 & 0 & 365 \\
Caatinga & 5 & 326 & 155 & 486 \\
Ecótono & 0 & 4 & 193 & 197 \\
Total & 350 & 350 & 348 & 1.048 \\
\hline Índice Kappa & 0.7365 & & Qualificação & Muito Bom \\
Acurácia Global & $82.4427 \%$ & & Qualificação & Excelente \\
\hline
\end{tabular}

A Caatinga teve um resultado perecido com os resultados anteriores, com maiores pontos de confusão com a classe Afloramento Rochoso. Já o Afloramento Rochoso teve pequenos pontos de confusão apenas com a classe Caatinga.

A acurácia do produtor e do usuário para a classe Ecótono foi de 55.45\% (Bom) e uma acurácia do usuário de 97.96\% (Excelente) e para classe Caatinga 93.14\% (Excelente) e 67.07\% (Muito Bom), resultados esse bem inferiores em comparação as mesmas classes mapeadas pelos classificadores anteriores. O Afloramento Rochoso apresentou também valores superiores a 90.00\% para ambos os critérios, demonstrando ser a classe de maior facilidade em distinção conforme o descrito no Quadro 9.

Quadro 9 - Acurácia do produtor e a Acurácia do usuário para o classificador Spectral Angle Mapper - SAM.

\begin{tabular}{ccccc}
\hline Classe Mapeada & $\begin{array}{c}\text { Acurácia do } \\
\text { Produtor em \% }\end{array}$ & $\begin{array}{c}\text { Acurácia do } \\
\text { Usuário em \% }\end{array}$ & $\begin{array}{c}\text { Acurácia do } \\
\text { Produtor por } \\
\text { Pixel }\end{array}$ & $\begin{array}{c}\text { Acurácia do } \\
\text { Usuário por } \\
\text { Pixel }\end{array}$ \\
\hline Afloramento Rochoso & 98.57 & 94.52 & $345 / 350$ & $345 / 365$ \\
Caatinga & 93.14 & 67.07 & $326 / 350$ & $326 / 486$ \\
Ecótono & 55.45 & 97.96 & $193 / 348$ & $193 / 197$ \\
Total & $100 \%$ & $100 \%$ & $864 / 1.048$ & $864 / 1.048$ \\
\hline
\end{tabular}

Yi et al. (2007) utilizaram o classificador SAM na identificação de áreas cultivadas por milho na região Sul do Brasil, assim como Vicente et al. (2012) na identificação de áreas de canade-açúcar, pasto e floresta para o estado de São Paulo, o que culminou segundo os autores em resultados satisfatórios para ambos, mesmo esses estudos não apresentando o método estatísticos clássico para validação de mapeamento como o Índice Kappa e Acurácia Global. No caso para Yi et al. (2007) os resultados foram avaliados por trabalho de campo e Vicente et al. (2012) a partir de regressão linear, onde ambos constataram a eficiência do mapeamento desenvolvido.

Campos et al. (2016) que também avaliaram diferentes classificadores na separação de alvos contendo formações vegetais, alcançaram de forma geral valores superiores a $60 \%$ de acerto com o classificador SAM, o que ajuda a corroborar os resultados obtidos neste estudo que foram superiores a 70\%, ressaltando que neste caso foram analisados apenas 3 classes para o mapeamento. Já Borges e Sano (2014) obtiveram o valor de Índice Kappa de 0,80 e de 84,00\% para Acurácia Global ao mapearem o uso e cobertura vegetal do Oeste da Bahia com foco na identificação das 
diferentes fitofisionomias vegetais, comparado com os valores obtidos neste estudo que se mostraram bem próximos ao obtido pelo referidos autores, ressaltando a eficiência do classificador SAM.

O classificador Nearest Neighbor apresentou o menor valor de Índice Kappa (0.6191) qualificado como Muito Bom e Acurácia Global (74.6183\%). Ao observar a matriz de confusão para a classe Ecótono, nota-se que o número de pontos confundidos com a classe Caatinga é maior que os três classificadores anteriores, dos 348 pontos de verdades terrestre para esta classe apenas 174 foram acertadas corretamente, as outras 169 foram confundidas com a classe Caatinga e também foi o que teve a maior confusão com a classe Afloramento Rochoso com 5 pontos. $\mathrm{O}$ Quadro 10 demonstra a Matriz de confusão para o classificador Nearest Neighbor.

Quadro 10 - Matriz de confusão do mapeamento desenvolvido pelo classificador Nearest Neighbor.

\begin{tabular}{ccccc}
\hline Nearest Neighbor & \multicolumn{2}{c}{ Classe Mapeada } & Pontos de Controle \\
\hline Classe Mapeada & Afloramento Rochoso & Caatinga & Ecótono & Total \\
Afloramento Rochoso & 283 & 22 & 5 & 310 \\
Caatinga & 67 & 325 & 169 & 561 \\
Ecótono & 0 & 3 & 174 & 177 \\
Total & 350 & 350 & 348 & 1.048 \\
Índice Kappa & 0.6191 & & Qualificação & Muito Bom \\
Acurácia Global & $74.6183 \%$ & & Qualificação & Muito Bom \\
\hline
\end{tabular}

A classe Caatinga foi a que mais obteve pontos corretos para este classificador. O Afloramento Rochoso foi a classe com menor número de acertos se comparados com os demais classificadores. O Quadro 11 demonstra os valores da acurácia de produtor e do usuário.

Quadro 11 - Acurácia do produtor e a Acurácia do usuário para o classificador Nearest Neighbor.

\begin{tabular}{ccccc}
\hline Classe Mapeada & $\begin{array}{c}\text { Acurácia do } \\
\text { Produtor em \% }\end{array}$ & $\begin{array}{c}\text { Acurácia do } \\
\text { Usuário em \% }\end{array}$ & $\begin{array}{c}\text { Acurácia do } \\
\text { Produtor por } \\
\text { Pixel }\end{array}$ & $\begin{array}{c}\text { Acurácia do } \\
\text { Usuário por } \\
\text { Pixel }\end{array}$ \\
\hline Afloramento Rochoso & 80.86 & 91.29 & $283 / 350$ & $283 / 310$ \\
Caatinga & 92.86 & 57.93 & $325 / 350$ & $325 / 561$ \\
Ecótono & 50.00 & 98.31 & $174 / 348$ & $174 / 177$ \\
Total & $\mathbf{1 0 0 \%}$ & $\mathbf{1 0 0 \%}$ & $\mathbf{7 8 2 / 1 . 0 4 8}$ & $\mathbf{7 8 2 / 1 . 0 4 8}$ \\
\hline
\end{tabular}

A classe Ecótono apresentou uma acurácia do produtor de $50.00 \%$ (Bom) e de $98.31 \%$ do usuário (Excelente). Para a Caatinga os valores de acurácia do produtor foram de $92.86 \%$ e de $57.93 \%$ do usuário. O Afloramento Rochoso também apresentou os menores valores de acurácia para produtor $(80.86 \%)$ e $91.29 \%$ para o usuário.

O aumento da confusão entre as classes ocorreu pelo fato da segmentação não conseguir separar alguns pixels que não pertencem a determinada classe no mesmo polígono, principalmente na classe Ecótono que teve alguns pixels agrupados referentes a classe Caatinga, evidenciando a 
dificuldade de separar tais alvos na segmentação, no qual optou-se por não coleta-los como amostras para o treinamento, o que pode ter influenciado posteriormente na classificação. Uma vez que para este estudo foi adotado como critério evitar qualquer tipo de edição ou correções dos resultados obtidos pelos classificadores.

Após vários testes realizados para ajustar a ferramenta de Composition of Homogeneity Criterion na árvore de processo (Process Tree) que leva em consideração atributos como escala, compacidade e a forma dos objetos a serem segmentados e no intuito de obter um melhor resultado, chegamos aos valores de limiares de 1 para escala, 0,006 para forma e 0,005 para compacidade, considerados os limites para esta segmentação, uma vez que valores menores que estes utilizados não segmentam os alvos de forma coerente, gerando polígonos muito pequenos que dificultam a coleta de amostras para o treinamento do classificador. Por se tratar de microambientes mais úmidos e formados predominantemente por vegetação de porte arbóreo, os Ecótonos desta região encontram-se geralmente em uma faixa muito estreita entre os Afloramentos Rochosos, o que dificultou o mapeamento a partir de técnicas de segmentação, mesmo utilizando uma imagem de satélite de 10 metros de resolução espacial, contudo o resultado do mapeamento está entre as margens de erro aceitáveis pelos parâmetros Kappa a partir dos limiares estabelecidos por Lands e Koch (1977).

Vários estudos (SOUSA et al., 2010; CORRÊA et al., 2017; CHELOTTI, 2017; LEITE et al., 2017) utilizando classificação orientada a objeto demostraram resultados satisfatórios para mapeamentos relacionados a vegetação. Silva e Bacani (2019b) utilizaram técnicas similares a partir da árvore de processo (Process Tree) e o classificador Nearest Neighbor para poder separar diferentes fitofisionomias na região do Pantanal, no qual obtiveram valores de Índice Kappa e Acurácia Global acima de 0,80, considerado excelente. Seabra et al. (2014) também utilizaram classificação orientada a objeto para mapear o uso e cobertura da terra na bacia hidrográfica do rio Taperoá, onde se encontra a área de estudo, obtendo também resultados satisfatórios no mapeamento, mesmo não apresentado os valores de validação estatística, mas que foram corroborados mediante a realização de trabalho de campo desenvolvido pelos autores, comprovando também a eficácia deste tipo de classificação para áreas maiores. Fica evidente que embora a abordagem de classificação orientada a objeto possua uma tendência de melhor desempenho de concordância estatística em várias áreas do Brasil e do mundo, sobretudo em áreas urbanas, no caso da Caatinga, isso não se concretizou. Isto se deve, em grande parte, a elevada heterogeneidade espectral apresentada pela área, que demandaria a consideração de elementos altamente exigentes em termos de processamento computacional, tal como a textura.

É importante também ressaltar a utilização da imagem do satélite SENTINEL-2A disponibilizada gratuitamente pela ESA (European Space Agency), possibilitando a redução dos 
custos para a pesquisa, além conter uma resolução espacial de 10 metros, o que permitiu o mapeamento dessas áreas de forma mais expressiva, uma vez que ao utilizar imagens de satélite com 30 metros de resolução espacial, como em geral tem ocorrido nos estudos do semiárido brasileiro, essas áreas são ocultadas, acarretando em prejuízos, principalmente quanto a delimitação de espaços a serem preservados na aplicação de políticas ambientais.

\section{CONCLUSÕES}

Os quatros classificadores apresentaram resultados satisfatórios e desempenhos qualificados como muito bom para o Nearest Neighbor e o Spectral Angle Mapper (SAM) e excelente para Support Vector Machine (SVM) e Neural Net avaliados pelo Índice Kappa e Acurácia Global e posteriormente pelos limiares de qualidade estabelecidos por Lands e Koch (1977).

Os resultados obtidos permitiram observar quais métodos de classificação e quais classificadores são mais eficientes para o mapeamento e a distinção das diferentes formações vegetais encontradas nessa região do semiárido nordestino brasileiro, principalmente os pequenos Ecótonos que se encontram nas áreas úmidas localizadas no entorno dos afloramentos rochosos.

Este tipo de registro cartográfico permite que elementos importantes da paisagem sejam anexados a outros documentos e sirvam de base para estudos mais detalhados sobre áreas de exceção do ponto de vista vegetal, como um reflexo das condições locais de maior umidade, dentro do domínio da Caatinga, além de ressaltar a importância da preservação desse ecossistema ainda pouco estudado, o que demonstra parte do tamanho do potencial natural e a riqueza da diversidade deste bioma endêmico do Brasil. Dessa forma, os resultados obtidos também se revestem de importância como base para a criação de políticas de preservação e principalmente na gestão desses recursos naturais dentro da APA do Cariri e outras UC's localizadas no semiárido brasileiro.

\section{AGRADECIMENTOS}

A CAPES pela bolsa de doutorado concedida através da FAPESQ EDITAL No 003/2016, processo 88887.369009/2019-00. Ao Programa de Pós-Graduação em Geografia da Universidade Federal da Paraíba. E a Universidade Federal de Mato Grosso do Sul, Campus de Três Lagoas pela parceria.

\section{REFERÊNCIAS}

AESA. Agência Executiva de Gestão das Águas do Estado da Paraíba. Geoportal. Shapefiles. Disponível em: <http://www.aesa.pb.gov.br/geoprocessamento/geoportal/shapes.html>. Acesso em: 19 de set. 2018. 
ANDRADE, A. C.; FRANCISCO, C. N.; ALMEIDA, C. M. Desempenho de classificadores paramétrico e não paramétrico na classificação da fisionomia vegetal. Revista Brasileira de Cartografia, v. 2, n. 66, p. 349-363, 2014.

ARRUDA, G. P.; DEMATTÊ, J. A. M.; CHAGAS, C. S. Mapeamento digital de solos por redes neurais artificiais com base na relação solo-paisagem. Revista Brasileira de Ciência do Solo. $n$. 37, p. 327-338, 2013.

AUGUSTO, R. C. A cartografia de paisagens e a perspectiva geossistêmica como subsídios ao planejamento ambiental. Revista Tamoios, v. 12, n. 1, p. 144-153, 2016.

BASTOS, F. H.; CORDEIRO, A. M. N. Fatores naturais da evolução das paisagens no semiárido brasileiro: uma abordagem geral. Revista Geonorte, v. 2, n. 5. p. 464-476, 2012.

BORGES, E. F.; SANO, E. E. Séries temporais de EVI do Modis para o mapeamento de uso e cobertura vegetal do Oeste da Bahia. Boletim de Ciências Geodésicas, v. 20, n. 3, p. 526-547, 2014.

CAMPOS, W. W.; GASPAR, J.; LAGE, M. O.; KAWASHIMA, R. S.; GIANNOTTI, M. A.; QUINTANILHA, J. A. Avaliação de classificadores de imagem de satélite a partir do uso de uma técnica de votação. Revista Brasileira de Cartografia, n. 68/8, p. 1653-1664, 2016.

CARVAlHO, M. G. Classificação geomorfológica do estado da Paraíba. João Pessoa: Universitária/Funap, 1982.

CHAGAS, C. S.; VIEIRA, C. A. O.; FERNANDES FILHO, E. I.; JUNIOR, W. Utilização de redes neurais artificiais na classificação de níveis de degradação em pastagens. Revista Brasileira de Engenharia Agrícola e Ambiental, v. 13, n. 3, p. 319-327, 2009.

CHELOTTI, G. B. Mapeamento de uso do solo da bacia hidrográfica do Alto Descoberto, no Distrito Federal, por meio de classificação orientada a objetos com base em imagem do satélite Landsat 8 e softwares livres. Revista Brasileira de Geomática, v. 5, n. 2, p. 172-185, 2017.

CONGALTON, R. G. A review of assessing the accuracy of classifications of remotely sensed data. Remote Sensing of Environment, v. 49, n. 12, p. 1671-1678, 1991.

CORDEIRO, J. M. P.; SOUZA, B. I.; FELIX, L. P. Levantamento florístico em afloramento rochoso no Piemonte da Borborema, Paraíba, Brasil. Revista Geosul, v. 33, n. 67, p. 215-228, 2018.

CORREA, L. C.; JUNIOR, H. T.; DALMAS, F. B.; PARANHOS FILHO, A. C. Avaliação de tipos de classificações em imagens de média e alta resolução espacial, no bioma Cerrado. Anuário do Instituto de Geociências, v. 40, n. 3, p. 05-13, 2017.

CPRM - SERVIÇO GEOLÓGICO DO BRASIL. Carta geológica folha SB.24-Z-D-III Boqueirão. Escala 1:100.000, 2017. Disponível em: <http://rigeo.cprm.gov.br/xmlui/ handle/doc/17654>. Acesso em: 17 ago. 2019.

ESRI. Environmental Systems Research Institute. ArcGIS for Desktop. Versão. 10.1. Redlands: ESRI, 2012. 
EXELIS. Visual Information Solutions. ENVI/software ENVI 5.1. Bolder, Colorado, 1 Cd Rom. 2014.

FERNANDES, M. R. M.; JUVANHOL, R. S.; BINOTI, D. H. B.; SILVA, G. F.; BERNANRDI, M.; BORGES, J. P. S.; LEITE, H. G. Aplicação de classificadores convencionais e rede neural artificial para mapeamento de uma imagem vant. Revista Geociências, v. 36, n. 4, p. 785-791, 2017.

FLORENZANO, T. G. Iniciação em sensoriamento remoto. 3 ed. São Paulo: Oficina de Textos, 2011. 128p.

GONÇALVES, M. L.; NETTO, M. L. A.; JUNIOR, J. Z.; COSTA, J. A. F. Classificação nãosupervisionada de imagens de sensores remotos utilizando redes neurais auto-organizáveis e métodos de agrupamentos hierárquicos. Revista Brasileira de Cartografia, v. 1, n. 60, p. 17-29, 2008.

HAIDAR, R. F.; FAGG, J. M. F.; PINTO, J. R. R.; DIAS, R. R.; DAMASCO, G.; SILVA, L. C. R.; FAGG, C. W. Florestas estacionais e áreas de ecótono no estado do Tocantins, Brasil: parâmetros estruturais, classificação das fitofisionomias florestais e subsídios para conservação. Acta Amazonica, v. 43, n. 3, p. 261-290, 2013.

KÖPPEN, W. P. Grundriss der Klimakunde (Outline of climate science). 1. ed. Berlin:Walter de Gruyter, 1931. 388p.nDisponível em: $<$ http://koeppen-geiger.vu-wien.ac.at/koeppen.html $>$. Acesso em: 13 set. 2018.

LACERDA, A. V.; SILVA, D. V.; GOMES, A. C.; DORNELAS, C. S. M.; BARBOSA, M. F. Riqueza florística de quintais agroflorestais no semiárido paraibano, Brasil. Revista Brasileira de Agroecologia, v. 13, n. 3, p. 90-100, 2018.

LANDIS, J. R.; KOCH, G. G. The measurement of observer agreement for categorical data. Biometrics, v. 33, n. 1, p. 159-174, 1977.

LEAL, I. R., SILVA, J. M. C., TABARELli, M., LACHER JR., T. E. Mudando o curso da conservação da biodiversidade na Caatinga do nordeste do Brasil. Megadiversidade, v. 1, n. 1, p. 139-146, 2005.

LEITE, L. R.; CARVAlHO, L. M. T.; SILVA, F. M. Change detection in forests and savannas using statistical analysis based on geographical objects. Boletim de Ciências Geodésicas, v. 23, n. 2, p. $284-295,2017$.

LIMA, F. S.; ALMEIDA, N. V. Dinâmica espaço-temporal da cobertura vegetal na Área de Proteção Ambiental (APA) do Cariri, Paraíba-PB, Brasil. Revista Brasileira de Geografia Física, v. 10, n. 3, p. 699-721, 2017.

LENZI, I. L. C.; NUNES, G. M. comparação entre os classificadores support vector machine e spectral angle mapper aplicado à diferenciação das fitofisionomias do parque estadual do Araguaia (MT). Revista Eletrônica Geoaraguaia, v. 6, n. 1, p. 99-114, 2016.

LUNGUINHO, R. L.; SOUZA, B. I.; QUEIROZ, R. T.; CARDOSO, E. C. M. A influência dos lajedos na composição florística do seu entorno, no sítio Salambaia - Cabaceiras - PB. Revista Equador, v. 4, n. 3, p. 230-237, 2015. 
MANANDHAR, R.; ODEH, I. O. A.; ANCEV, T. Improving the accuracy of land use and landcover classification of Landsat data using post-classification enhancement. Remote Sensing. $n$. 1, p. 330-344, 2009.

MIGUEL, B. H.; SANO, E. E. Classificação do uso e cobertura da terra do Distrito Federal, Brasil a partir de dado de coerência interferométrica. Revista Brasileira de Geografia Física, v. 12, n. 02, p. 427-442, 2019.

MOREIRA, A. A.; FERNANDES, F. H. S.; NERY, C. V. M. Aplicação do algoritmo support vector machine na análise espaçotemporal do uso e ocupação do solo na bacia do Rio Vieira. Caminhos de Geografia, Uberlândia, v. 15, n. 50, p. 152-163, 2014.

PARAÍBA. Decreto $\mathbf{n}^{\mathbf{0}} \mathbf{2 5 . 0 8 3}$, de 08 de junho de 2004. Dispõe sobre a criação da Área de Proteção Ambiental do Cariri. João Pessoa, 2004. Disponível em:<http://www.sudema.pb.gov.br $>$. Acesso em 18: set. 2018.

PEREIRA, G. H. A.; CENTENO, J. A. S. Avaliação do tamanho de amostras de treinamento para redes neurais artificiais na classificação supervisionada de imagens utilizando dados espectrais e laser scanner. Boletim de Ciências Geodésicas. v. 23, n. 2, p. 268-283, 2017.

POREMBSKY, S.; SEINE, R.; BARTHLOTT, W. Factors controlling species richness of inselbergs. Inselbergs: Biotic Diversity Outcrops in Tropical and Temperate Regions. v. 146, p. 451- 482, 2000.

QGIS. Development Team. QGIS/software QGIS 3.0. Disponível em: $<$ https://www.qgis.org /pt_BR/site/>. Acesso em: 10 out. 2018.

ROMANO, M. P. C. G.; ROCHA, J. G.; SANTOS, M. L. F.; SOUZA, M. C. S. Unidades paisagísticas no semiárido paraibano: porção Leste do Plúton Bravo, Cabaceiras-PB. In: CONGRESSO INTERNACIONAL DA DIVERSIDADE DO SEMIÁRIDO, 2., 2018, Paraíba. Anais... Paraíba: Realize Eventos e Editora, 2018. p. 1-10.

SARTHOU, C; SAMADI, S.; BOISSELIER-DUBAYLE, M-C. Genetic structure of the saxicole Pitcairnia geyskesii (Bromeliaceae) on inselbergs in French Guiana. American Journal of Botany. v. 88, p. 861-868, 2007.

SEABRA, V. S.; XAVIER, R. A.; DAMASCENO, J. DORNELLAS, P. C. Mapeamento do uso e cobertura do solo da bacia do rio Taperoá: região semiárida do estado da Paraíba. Caminhos da Geografia, Uberlândia, v. 15, n. 50, p. 127-137, 2014.

SENTINEL 2A: imagem de satélite. Copernicus: ESA - European Space Agency, 2015. 1 fotografia área. Escala 1:25.000. Bandas 2, 3, 4, e 8. Disponível $\mathrm{m}:<$ https://scihub.copernicus.eu/dhus/\#/home>. Acesso em: 19 mai. 2018.

SILVA, A. M.; SILVA, J. S. V.; LUCIANO, A. C. S. Distribuição dos contatos florísticos e refúgios vegetacionais no Pantanal brasileiro. In: SIMPÓSIO DE GEOTECNOLOGIAS NO PANTANAL, 3., 2010, Cáceres. Anais... Cáceres: EMBRAPA/INPE, 2010. p. 35-36.

SILVA, L. F.; SOUZA, B. I.; BACANI, V. M. Intensidade da ação antrópica na área de proteção ambiental do Cariri Paraibano. Caminhos da Geografia, Uberlândia, v. 20, n. 71, p. 364-383, 2019a. 
SILVA, L. F.; BACANI, V. M. Utilização de técnicas de classificação orientada a objeto no mapeamento do uso da terra e cobertura vegetal no Pantanal de Aquidauana. Boletim de Geografia. v. 37, n. 1, p. 214-233, 2019 b.

SILVA, E. P.; SOUZA, E.; PEREIRA, R. M.; CANTARUTTI, R. B.; FERNANDES FILHO, E. I. Algoritmos de classificação de imagem no mapeamento de pastagem em diferentes estádios de degradação. Revista Brasileira de Cartografia, v. 1, n. 65, p. 51-63, 2013.

SOTHE, C.; LIESENBERG, V.; ALMEIDA, C. M.; SCHIMALSKI, M. C. Abordagens para classificação do estádio sucessional da vegetação do parque nacional de São Joaquim empregando imagens Landsat-8 e Rapideye. Boletim de Ciências Geodésicas, v. 23, n. 3, p. 389-404, 2017.

SOUZA, N. R. L.; XAVIER, R. A. A importância dos "lajedos" na paisagem geomorfológica do Cariri Paraibano. In: SIMPÓSIO BRASILEIRO DE GEOGRAFIA FÍSICA APLICADA, 17., 2017, Campinas. Anais... Campinas: UNICAMP/IG, 2017. p. 6561-6566.

SOUZA, B. I.; SOUZA, R. S. Processo de ocupação dos Cariris Velhos - PB e efeitos na cobertura vegetal: contribuição à Biogeografia Cultural do semiárido. Revista Caderno de Geografia, Belo Horizonte, v. 32, n . 2, p. 229-258, 2016.

SOUZA, A. M. O.; MESQUITA, P.; GONÇALVES, A. C.; SILVA, J. R. M. Segmentação e classificação de tipologias florestais a partir de imagens QUICKBIRD. Ambiência, v. 6, Ed. Especial. p. 57-66, 2010.

SOUZA, B. I.; SUERTEGARAY, D, M.; LIMA, E. A. Desertificação e seus efeitos na vegetação e solos do cariri paraibano. Mercator - Revista de Geografia da UFC, v. 08, n. 16, p. 217-232, 2009.

TRIMBLE GEOSPATIAL. Software eCognition Developer 8.0. Disponível em: $<$ http://www.ecognition.com/suite/ecognition-developer>. Acesso em: 16 abr. 2017.

VEloso, H. P.; RANGEL FILHO, A. L. R.; LIMA, J. C. A. Classificação da Vegetação Brasileira: adaptada a um sistema universal. 1. ed. Rio de Janeiro: IBGE, 1991. 112p.

VICENTE, L. E.; GOMES, D.; VICTORIA, D. C.; GARÇON, E. A. M.; BOLFE, E. L.; ANDRADE, R. G.; SILVA, G. B. S. Séries temporais de NDVI do sensor SPOT Vegetation e algoritmo SAM aplicados ao mapeamento de cana-de-açúcar. Pesquisa Agropecuária Brasileira, v. 47, n. 9, p. 1337-1345, 2012.

YI, J. L. R.; SHIMABUKURO, Y. E.; QUINTANILHA, J. A. Identificação e mapeamento de áreas de milho na região Sul do Brasil utilizando imagens Modis. Engenharia Agrícola, v. 27, n. 3, p. 753-763, 2007.

Trabalho enviado em 09/09/2019

Trabalho aceito em 09/10/2019 